\title{
Prevalence and Nature of Musculoskeletal Injuries in Female Basketball Players
}

\author{
Vibha Jadhav', Geeta Bhatt ${ }^{2}$ \\ ${ }^{1}$ Intern, K.J. Somaiya College of Physiotherapy, \\ ${ }^{2}$ Professor and Head of Department of Neurophysiotherapy, K.J. Somaiya College of Physiotherapy, Mumbai. \\ Corresponding Author: Vibha Jadhav
}

\begin{abstract}
Background: The aim of study was to look into the frequency and nature of on-court injuries in female basketball players (FBP) and to determine the most common on-court injuries as well as their anatomical locations.

Method: cross sectional descriptive survey study design adopted. The data was gathered through the use of a structured self -administered questionnaire in the form of Google form via social media platforms (WhatsApp, Instagram, Facebook) and e-mail. Using total population sampling design, 40 participants were calculated who filled the form. The collected data were analysed using descriptive analysis.
\end{abstract}

Result: The study found that the commonest injured anatomical area was the ankle (32\%) and the commonest nature of injury was joint (22.2\%) followed by muscle $(20.9 \%)$.

Conclusion: The study concludes that the lower extremity injuries were the most common. It identified the ankle injuries to be the commonest injuries occurring in female basketball players.

Key Words- Female basketball players, ankle injuries, basketball, on-court injuries.

\section{INTRODUCTION}

Basketball was invented in 1891 by Canadian American gym teacher James Naismith, in the United States. This sport has evolved to become world's one of the most popular and widely used sport. It is a game played between two teams of five players each on a rectangular court. Each team tries to score by tossing the ball through the opponent's goal, an elevated horizontal hoop and net called the basket ${ }^{[1-}$ 2].

It is a sport that primarily entails actions such as running, changes of direction, lateral movements, jumping and in particular, the impact of landing, all of which are susceptible to injury ${ }^{[3]}$.

Women's participation in sports, particularly basketball, is growing in popularity, making it even more vital to understand the potential risks of injury in that discipline ${ }^{[4]}$.

In comparison to male basketball players, few researches have been conducted on female basketball players. The physical and biomechanical distinctions between them necessitate more research in female athletes ${ }^{[5]}$.

Basketball is becoming increasingly popular with women in several nations, including India. In India, it is still regarded as a young sport. As a result, it is important to know what kind of injuries female basketball players are most prone to sustain and when they happen.

Avoiding injuries and, if they do occur, receiving proper care and treatment in order to return to sport is essential for optimal performance. Even if an injury develops, many of them go unnoticed until they become severe. Coaches are often the 
first referrals in many situations, and there is little awareness about physiotherapy in injury instances in India.

Shoulder, wrist, and fingers are the most prevalent upper limb injuries, whereas knee and ankle injuries are the most common lower limb-limb injuries. ${ }^{[6-9]}$.

The player's on-court position (centre, point guard, shooting guard, small forward, power forward) at the time of injury has an impact and /or provides information on the injury mechanism ${ }^{[10]}$.

Warmup and cooldown also play an important role in injury prevention; hence they must be emphasised ${ }^{[11-12]}$.

Overuse injuries arise when a player is overworked for an extended period of time. As a result, it is critical to understand the nature and types of injuries that FBP sustain $^{[13-14]}$.

The goal of the study was to collect data on various injuries that occurred oncourt during a game in FBP, as well as to assess the prevalence, nature, and anatomical location of these injuries. This research can be used to develop and implement corrective and preventive strategies in training sessions.

\section{METHODOLOGY}

The study was employed using descriptive, cross sectional survey design. The study was conducted over a period of 6 months and the study population were FBP. Sample size was calculated using from openepifree source calculator Version 3 in which:

The anticipated proportion of commonest injuries was $80 \%$.

Absolute precision of $12 \%$.

Design effect $=1$ (for random sample)

Confidence level $=95 \%$

Minimum sample size obtained $=41$ (using openEpi source calculation).

The exclusion criteria included injuries that occurred while training in gym, training sessions or while playing any other sport.

\section{PROCEDURE}

The questionnaire was validated by 3 subject expertise (faculty members).
The Institutional Review Board of K.J. Somaiya College of Physiotherapy gave their approval.

A predesigned and pre-validated Questionnaire was distributed in the google form format via social media (WhatsApp, Instagram, Facebook) among the population according to the inclusion criteria which included FBP in the age group of 15-28 years old and injuries that have occurred since the time they have started playing basketball.

The questionnaire included 3 major sections as follows:

1. Demographic data

2. Fitness screening

3. About the sustained injury

The participants' consent was obtained by asking them to say "yes" or "no" to indicate their willingness to participate voluntarily. After confirmation the participants were directed to the questionnaire. Confidentially was ensured for all participants enrolled in this study. Data collected was analysed using descriptive statistics.

\section{Statistical Analysis}

Microsoft Excel was used to enter the data and analyse it. Descriptive statistics were used to analyse the data obtained. The frequency method was used to summarise and present the data. Tables, graphs, pie charts were used to show the percentages.

\section{RESULTS}

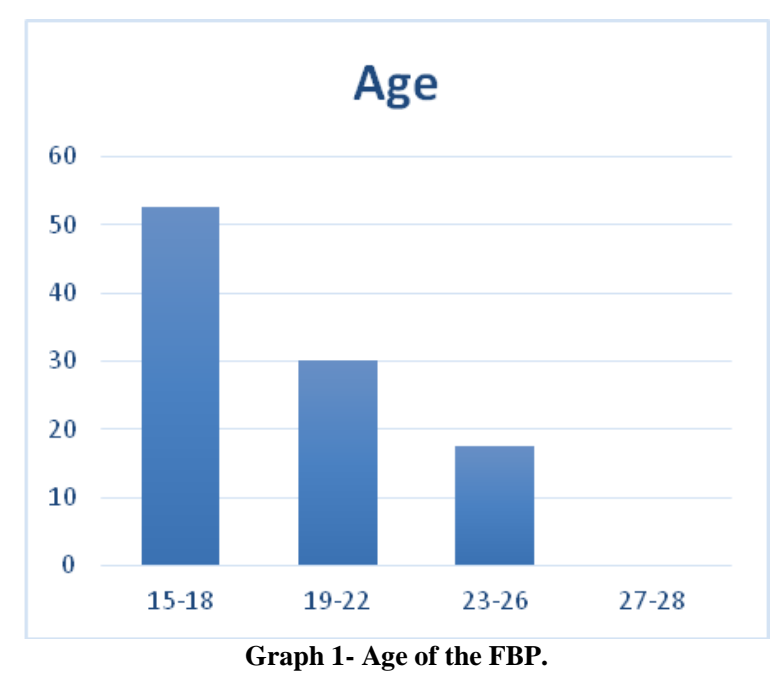


Twenty-two of the forty players who filled the form had more than one injury. A total of eighty-one injuries were sustained by these forty players.
The mean age was found to be 18.95 years. Majority of the players were playing since the period of 4-7 years.

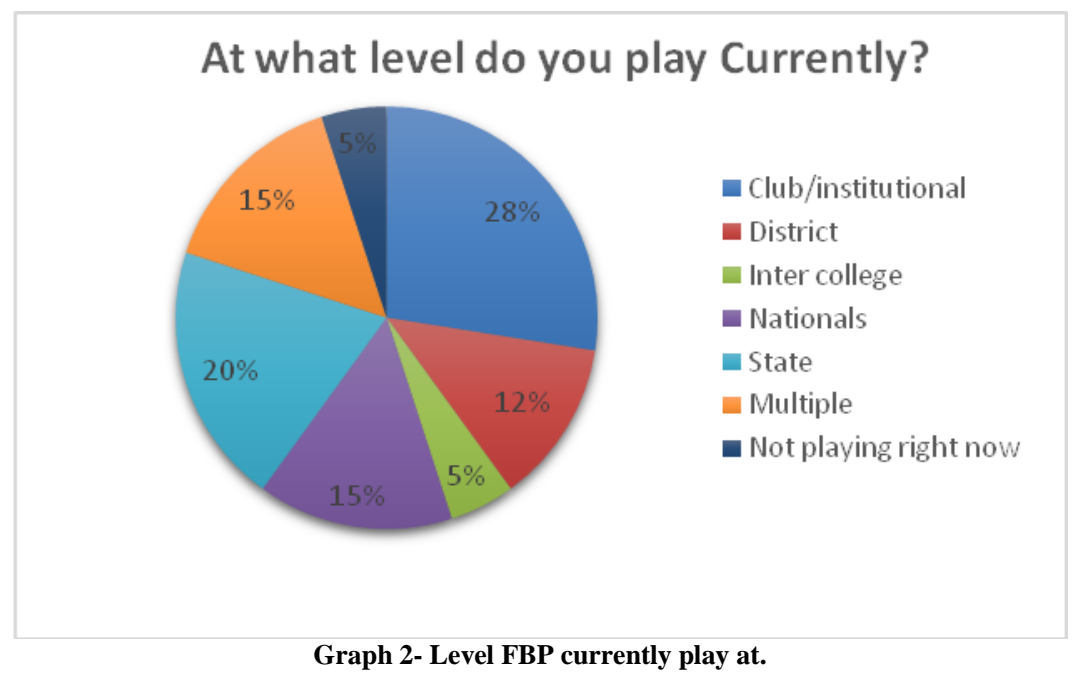

Highest population was found to be playing at the club/institutional level (28\%), followed by state level (20\%), followed by national and multiple levels accounting for $15 \%$ each.
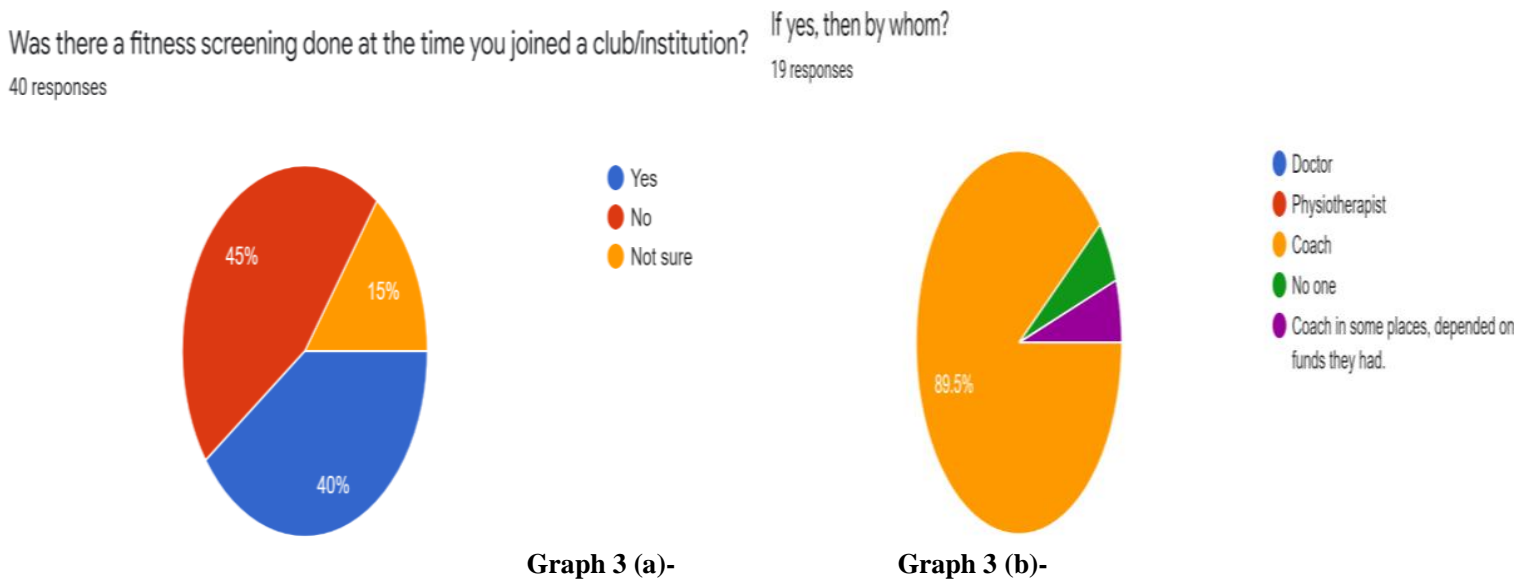

Graph 3 (a)-

$$
\text { Graph } 3 \text { (b)- }
$$

Do you get regular screening done?

40 responses

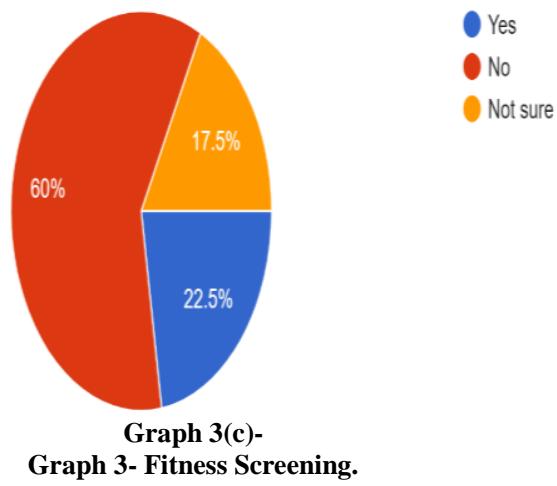


In the fitness screening section, $40 \%$ of the population responded that no fitness screening was done at the time they joined the club/institution and $15 \%$ were not sure if fitness screening was done. And if was done at all, $89.5 \%$ responded it was by their coaches.

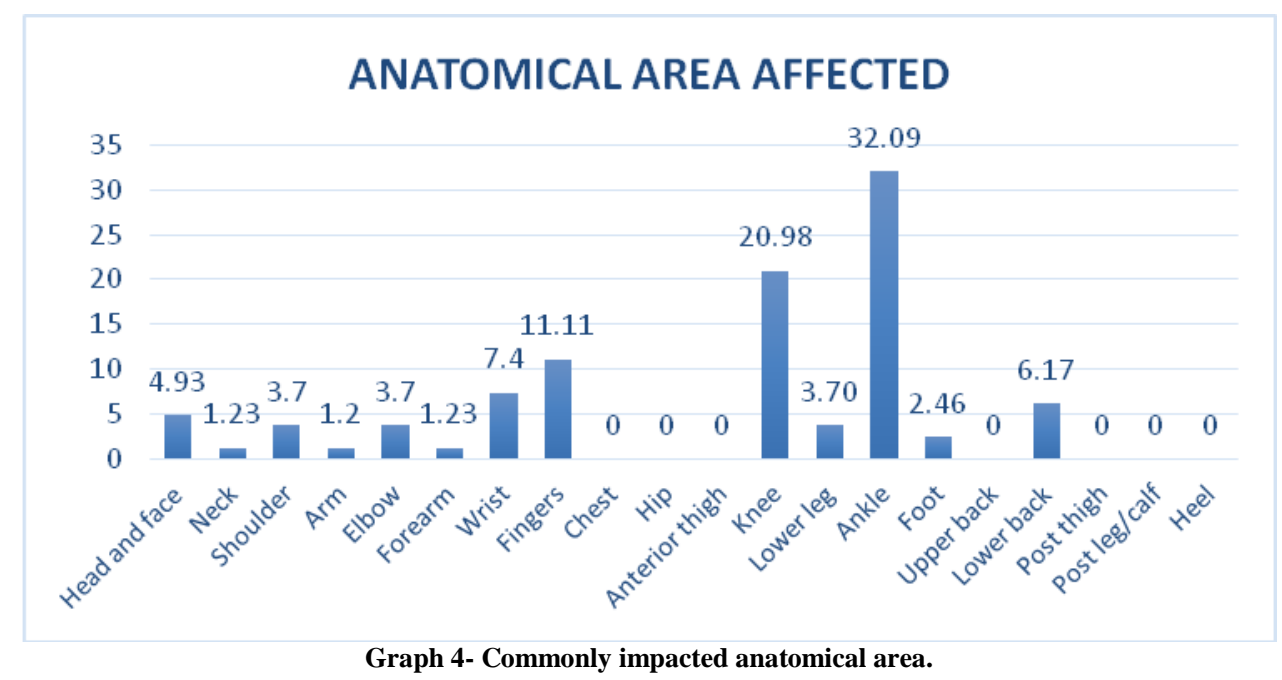

The commonest anatomical location injured which is to be the ankle $(32.09 \%)$ followed by knee $(20.98 \%)$ followed by fingers $(11.11 \%)$.

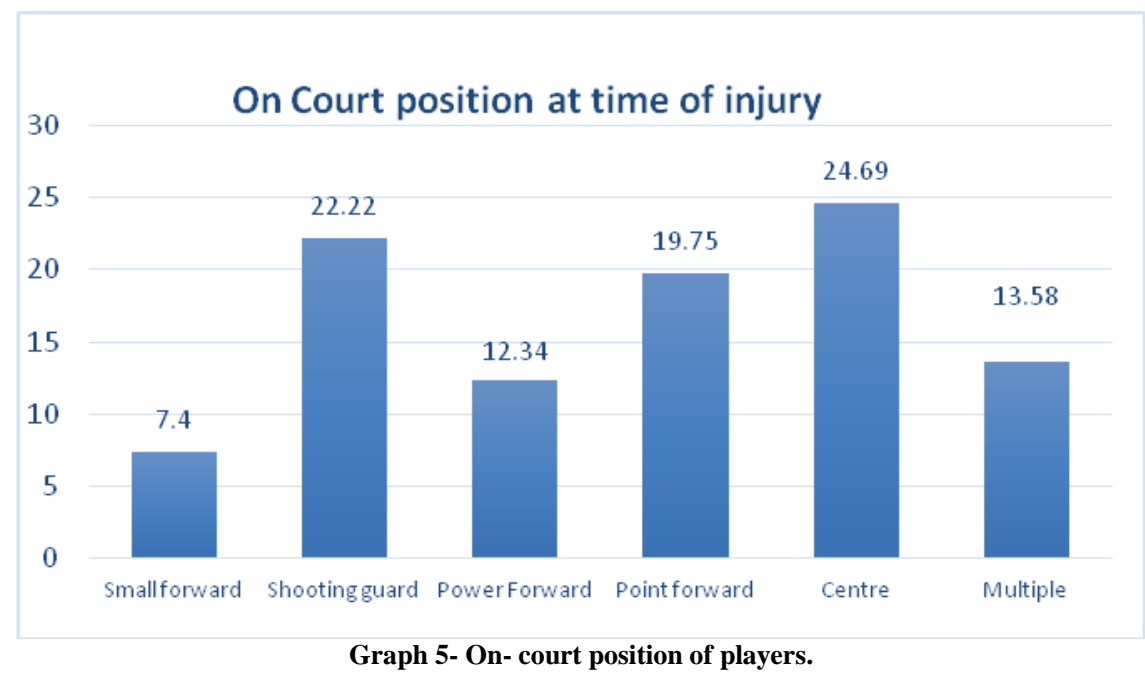

The commonest on court position during a match that sustained injury was to be of centre $(24.69 \%)$ followed by shooting guard $(22.22 \%)$ and point forward $(19.75 \%)$.

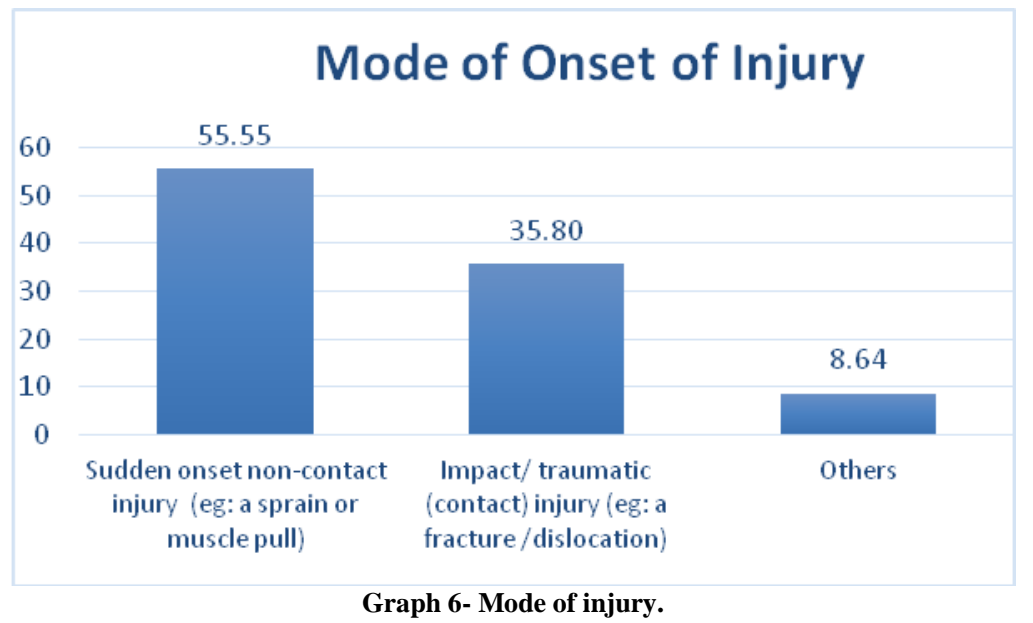


The graph shows that the most prevalent type of injury is sudden onset noncontact injury, which accounts for $55.55 \%$ of all injuries recorded.

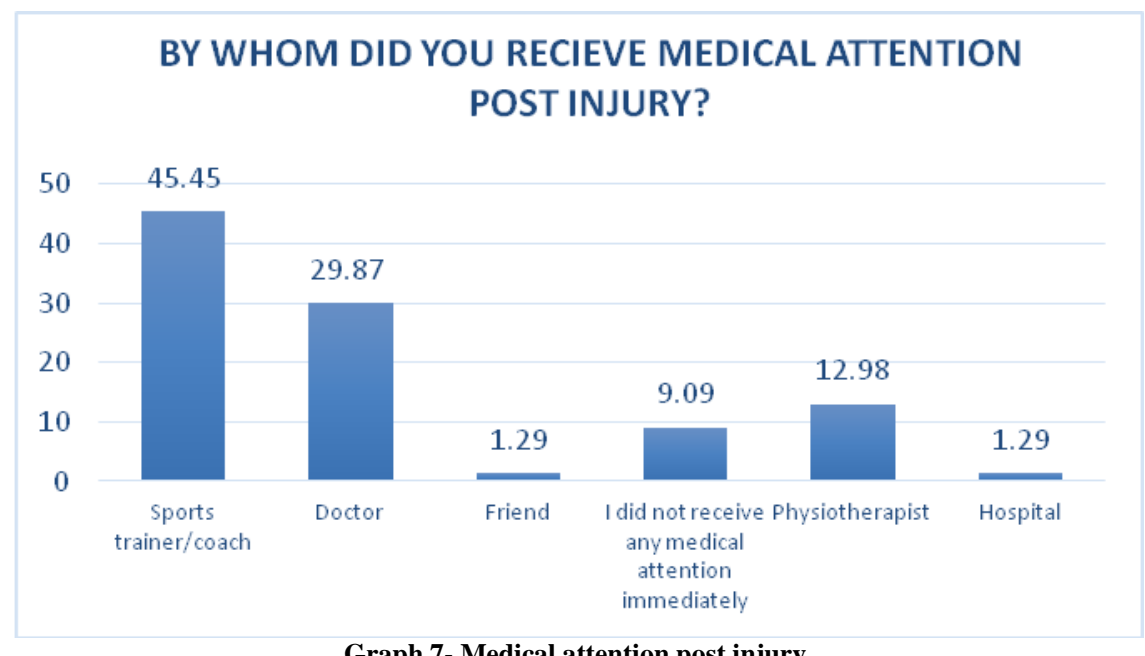

Graph 7- Medical attention post injury.

The sports trainer/coaches were the first point of contact for treating on-court injuries accounting for $45.45 \%$.

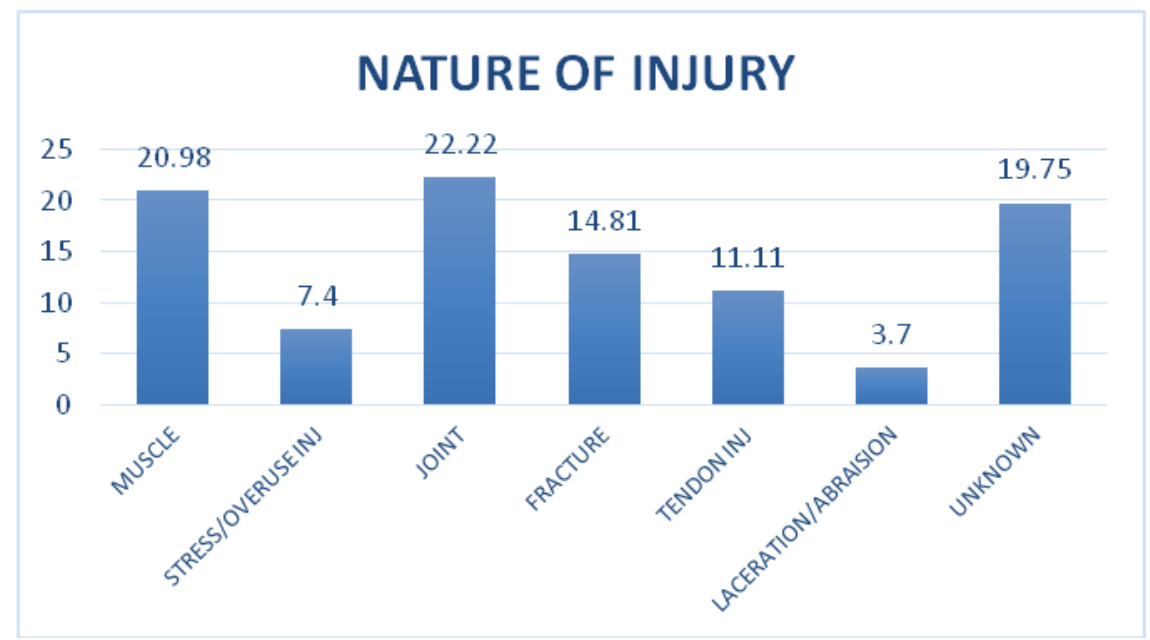

Graph 8- Nature of injury.

The most prevalent nature of injury was at the joints $(22.22 \%)$, followed by muscles (20.98\%). And there were a considerable number of injuries for which the cause was unknown.

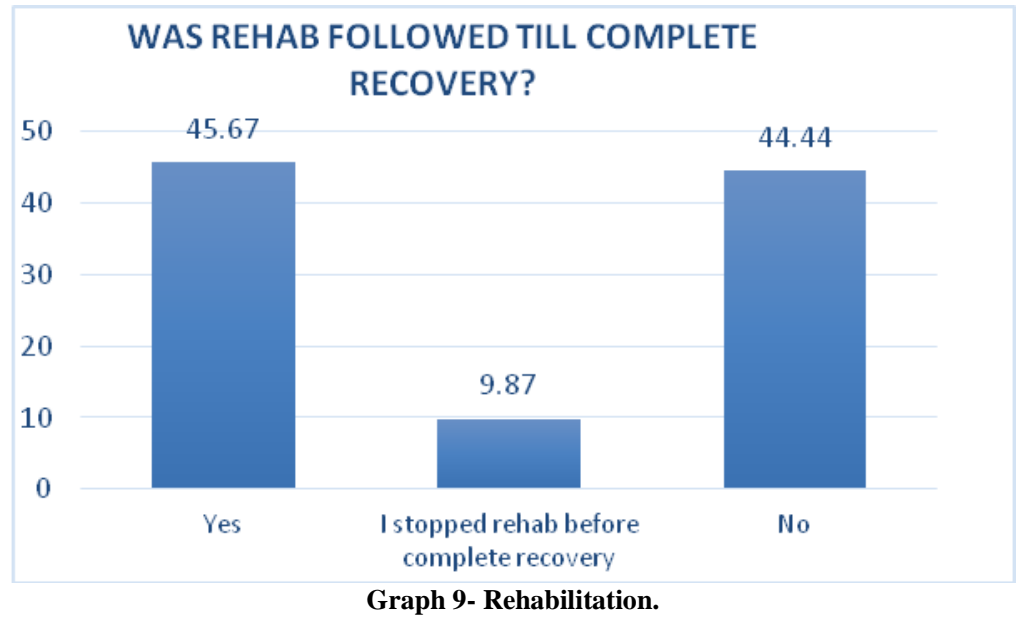


$44 \%$ of the injured didn't pursue rehabilitation at all until they were fully recovered, and $9.87 \%$ stopped Rehabilitation in the middle of their recovery.

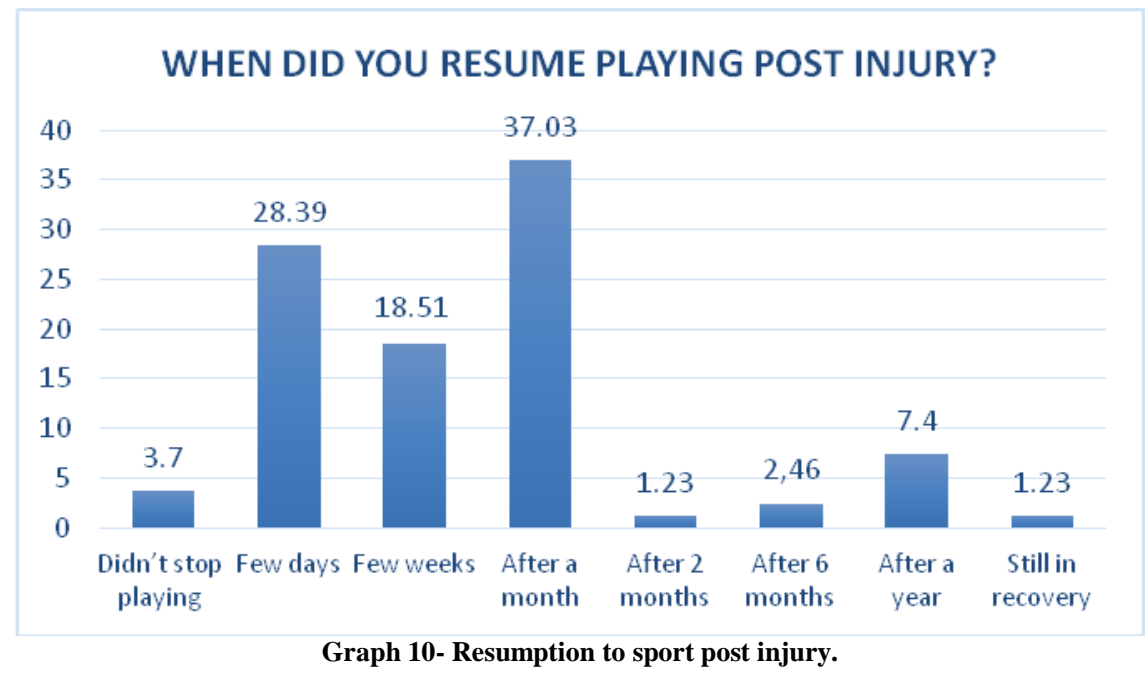

$37.03 \%$ players returned to play after a month, while $28.39 \%$ returned after a few days, and $18.5 \%$ after a few weeks.

\section{DISCUSSION}

This research has been completed by analysing and comparing the overall and specific injuries in female basketball players. Data from this study was gathered during period of six months. A total of forty people completed the study, with a total of eighty-one injuries reported. More over half of the participants $(50 \%)$ said they had more than one injury. The study's goal was to determine the frequency, nature, most prevalent body area, and anatomical location of on-court injuries in FBP.

According to a study, the frequency of injuries in practice sessions was much higher than the number of injuries during games ${ }^{[15]}$. Players spend more time in practice sessions than they do on the court during a competition, thus it is possible that, in terms of exposure, they are hurt substantially more during practise sessions, and therefore more data is available. As a result, the focus of this research was on court injuries during a match.

With basketball in India gaining more knowledge especially in the female players there is need to understand the type and nature of injury most likely to occur and under what circumstances they do occur.
Considering different anatomical locations and body areas a large portion of literature addressing basketball report lower limbs as the body part with higher incidence of injuries, specifically knee and ankle sprains [16-17]. In this study, it was confirmed, where lower extremity injuries have been observed in more than $50 \%$ of players in which ankle injuries $32.09 \%$ were reported as the commonest injured anatomical location followed by knee injuries $20.98 \%$. This could be associated to the fact that basketball is a high intensity intermittent team sport, requiring repeated sprints, jumps and landings, accelerations and decelerations which contribute to the onset of injuries in the lower extremities.

Additional injuries sustained included fingers $11.1 \%$, wrist $7 \%$, shoulder and elbow accounting for $3.7 \%$ each, arm and forearm $1.23 \%$ each, which could be attributed to the fact that there is involvement of upper extremities in handling the ball. The upper extremity skill set includes dribbling, passing, shooting, rebounding all of which can lead to risk of injuries based on continuous repetition of these movements during the matches ${ }^{[18-19]}$ followed by lower back $6 \%$ and head and face $4.9 \%$.

The lower extremity is most frequently injured area specific to ankle and knee leaded to time loss in players as the 
data collected showed that $37 \%$ injuries required a period of one month to recover completely.

It was also discovered that players who played at the centre position sustained the most injuries, accounting for $24.69 \%$ of all injuries reported, followed by shooting guards with $22.22 \%$ s and point forwards with $19.75 \%$. Similar results were found in many studies ${ }^{[10]}$. Sports injuries among adolescent basketball players according to position on the court. In comparison, centre position players are more likely to sustain injuries because they play in the key area. This could be due to the amount of time athletes spend in this area, which results in more exposure time, as well as the fact that game play in this area involves jumps, landings (from jump shots, layups, and rebounds), and player to player contact (in defence and offence) ${ }^{[15]}$.

The results from the study also showed that sports trainer/coach was the first contact person post an injury on-court and hence a sports physiotherapist or a medical practitioner would be a better person to handle the situation.

This study helps and provides information about on-court injuries in FBP and hence suggests to put more focus on prevention of these injuries.

This research also lays the groundwork for future studies on professional female basketball players.

There is also the possibility of using a computerised injury surveillance system to track, trace, and monitor injuries.

\section{Limitation}

As it was an instantaneous study, we could not analyse the injuries during particular leagues or tournaments.

The study could not calculate or note the exact match time loss as a large no. of players resumed playing after a month after an injury.

\section{CONCLUSION}

According to the findings, lower extremity injuries were the most common. It was discovered that ankle injuries are the most common among female basketball players. It also found that the most prevalent type of injury is to the joint.

\section{ACKNOWLEDGEMENT}

My project adviser, Dr Geeta Bhatt (PT), professor, is to be thanked for her sincere efforts, recommendations, and advice. I would also like to express my gratitude to all of my participants for their significant contributions to my research.

\section{Declarations}

Funding: The study Received no outside funding.

Conflict of Interest: None declared.

Ethical Approval: The study was approved by the Institutional Research Board Committee of K.J. Somaiya College of Physiotherapy.

Abbreviations: $\mathrm{FBP}=$ Female Basketball Players.

\section{REFERENCES}

1. Griffiths, Sian "The Canadian Who Invented Basketball”. BBC News. September 20, 2010.

2. Logan, R. G., Donald, Larry W. And Mokray, William George (2021, April29). Basketball, Encyclopedia Britannica.

3. "Basketball Injuries. "World Of Sports Science. Retrieved June 19, 2021 From https://www.encyclopedia.com/sports/sports -fitness-recreation-and-leisuremagazines/basketball-injuries

4. Hosea, Timothy M. MD; Carey, Christopher C. MD; Harrer, Michael F.MD: The Gender Issue: Epidemiology Of Ankle Injuries In Athletes Who Participate In Basketball. Clinical Orthopaedics and Related Research March 2000-Volume 372- Issue- Pg45-49.

5. Zelisko JA, Noble HB, Porter M. A Comparison of Men's and Women's Professional Basketball Injuries. Am J Sports Med. Sep-Oct 1982;10(5):297-9.

6. Starkey C. Injuries and Illnesses in The National Basketball Association: A 10-Year Perspective. J Athl Train. 2000; 35:161167. [PMC Free Article] [Pubmed] [Google Scholar] 
7. Deitch JR, Starkey C, Walters SL, Moseley JB. Injury Risk in Professional Basketball Players: A Comparison of Women's National Basketball Association and National Basketball Association Athletes. Am J Sports Med. 2006; 34:1077-1083. [Pubmed] [Google Scholar]

8. Meeuwisse WH, Sellmer R, Hagel BE. Rates And Risks of Injury During Intercollegiate Basketball. Am J Sports Med.

9. Borowshi L.A., Yard E.E., Fields S.K. The Epidemiology of US High School Basketball Injuries, 2005-2007. Am. J. Sports. Med. 2008; 36:2328-2335. Doi: 10.1177/0363546508322893. [Pubmed]

[Crossref] [Google Scholar]

10. Vanderlei FM, Bastos FN, De Lemes ÍR, Vanderlei LC, Júnior JN, Pastre CM. Sports Injuries Among Adolescent Basketball Players According to Position on The Court. Int Arch Med. 2013;6:5. [PMC Free Article] [Pubmed] [Google Scholar].

11. Shellock FG, Prentice WE. Warming-Up and Stretching for Improved Physical Performance and Prevention of SportsRelated Injuries. Sports Med 1985 JulyAugust;2(4):267-78.

12. Woods K, Bishop P, Jones E. Warm-Up and Stretching in The Prevention of Muscular Injury. Sports Med 2007;37(12):1089-99.

13. Leppanen M, Pasanen K, Kujala UM, Parkkari J. Overuse Injuries in Youth Basketball and Floor Ball. Open Access J Sports Med, 2015 May 22; 6:173-9.

14. Aicale R, Tarantino D, Maffulli N. Overuse Injuries in Sport: A Comprehensive
Overview. J Ortho Surg Res. 2018 Dec 5;13(1):309.

15. Nikolaos Kofotolis, and Eleftherios Kellis. Ankle sprain injuries:A 2 -year prospective cohort study in female Greek professional basketball players. Journal of athletic training, 2007, July-sept;42(3), 388-394.

16. Dick R., Hertel J., Agel J., Grossman J., Marshall S.W. Descriptive epidemiology of collegiate men's basketball injuries: National collegiate athletic association injury surveillance system, 1988-1909 through 2003-2004. J. Athl. Train. 2007; 42:194-201.

17. Silva A.S., Bdalla R.J., Fisberg M. Incidence of musculoskeletal injuries in elite female basketball athletes. Acta Orthop. Bras. 2007; 15:43-46.

18. Fraser MA, Grooms DR, Guskiewicz KM, Kerr ZY. Ball-contact injuries in 11 National Collegiate Athletic Association sports: the Injury Surveillance Program, 2009-2010 through 2014-2015. J Athl Train. 2017;52(7):698-707.

19. Dragoo JL, Braun HJ, Bartlinski SE, Harris AHS. Acromioclavicular joint injuries in National Collegiate Athletic Association football: data from the 2004-2005 through 2008-2009 National Collegiate Athletic Association Injury Surveillance System. Am J Sports Med. 2012;40(9):2066-2071.

How to cite this article: Jadhav V, Bhatt G. Prevalence and nature of musculoskeletal injuries in female basketball players. Int $J$ Health Sci Res. 2021; 11(9): 10-17. DOI: https://doi.org/10.52403/ijhsr.20210902 